\title{
VALIDATION OF A WIDE PLATE FINITE ELEMENT MODEL USING DIGITAL IMAGE CORRELATION
}

\author{
K. De Keyser ${ }^{1}$, F. Van Acker ${ }^{1}$, S. Hertele ${ }^{2}$, M. Verstraete ${ }^{3}$, W. De Waele ${ }^{3}$, R. Denys ${ }^{3}$ \\ ${ }^{1}$ Ghent University, Belgium \\ ${ }^{2}$ FWO Aspirant, Ghent University, Laboratory Soete, Belgium \\ ${ }^{3}$ Ghent University, Laboratory Soete, Belgium
}

\begin{abstract}
To investigate the influence of global plastic deformations on girth weld defect tolerance in pipelines, a parametric finite element model has been developed. This paper provides an experimental validation of the model. It describes the test setup and instrumentation used for the evaluation of plastic strain fields around a notch in a tension loaded non-welded X65 mini wide plate. LVDT measurements and digital image correlation (DIC) results are compared to each other and to the results of finite element simulations. Whereas some deviation is observed owing to unavoidable experimental uncertainties and limitations of finite element modelling, the overall correspondence is more than satisfying.
\end{abstract}

Keywords digital image correlation, unloading compliance, strain concentration, mini wide plate, finite element method

\section{INTRODUCTION}

As energy consumption is still increasing, more and more oil and gas sources are exploited in less accessible areas like arctic regions. Pipelines, connecting these sources with civilization, need to cross harsh environments and are thereby subjected to large deformations, for instance due to earthquakes or ground settlements [1]. These deformations exceed the deformations anticipated in stress-based design, usually limited to a maximum longitudinal strain of $0.5 \%$ [2]. For this reason, a so-called strain-based design is preferred over a traditional stress-based design.

An important aspect of this design methodology is that strain should not be concentrated in certain critical regions of the welded pipe. As weld flaws are inevitable, large strains must be avoided in their surroundings to prevent crack initiation and (un)stable growth.

Research at Laboratory Soete is focused on the deformation capacity and defect tolerance of pipeline girth welds in the context of strain-based design approach. This experimental based research is performed using so-called curved wide plate (CWP) tests. This can be described as a tensile test on a cut-out from a real pipeline, including a defective girth weld.

Recently, a parametric finite element (FE) model was developed, but experimental validation is required. Since CWP tests are expensive and large equipment is required, smaller test coupons, further called mini wide plates (MWP), offer satisfying accuracy and make tensile testing more convenient.

In this paper, such a mini wide plate test is thoroughly evaluated. The first section discusses the preparation of the specimen, the equipment and instrumentation that was used and the execution of the test. Afterwards, different measurement results are interpreted and compared to results of finite element simulations.

\section{PREPARATION AND EXECUTION OF THE TEST}

\section{$2.1 \quad$ Specimen}

A mini wide plate specimen was cut from an API 5L [3] X65 flat steel plate of $14.6 \mathrm{~mm}$ nominal thickness. A $25 \mathrm{~mm}$ long by $3 \mathrm{~mm}$ deep semi-elliptical surface crack was milled in the centre of the MWP. Blocks were welded to each specimen end for mounting purposes (Figure 1). The dimensions of the specimen are indicated in Figure 2. 


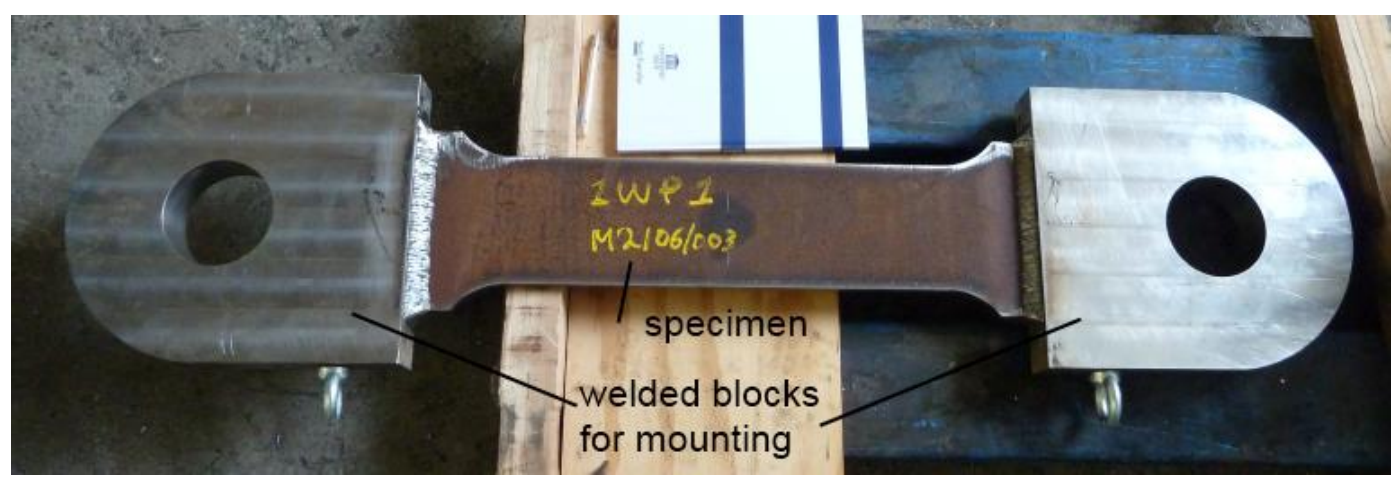

Figure 1: Test specimen with mounting blocks

\subsection{Material}

The stress-strain relation (average of 6 tensile tests) of the pipeline steel in the longitudinal direction is shown in Figure 3. The plate material exhibits discontinuous yielding behaviour with a pronounced Lüders plateau. The main tensile characteristics are listed in Table 1. Note that the yield-to-tensile stress ratio ( $Y / T$ ratio) is defined as the ratio between $0.2 \%$ proof stress $R_{p 0.2}$ and ultimate tensile stress $R_{m}$.

Table 1: Mechanical properties of API $5 \mathrm{~L}$ X65 pipeline steel

\begin{tabular}{|c|c|c|c|c|}
\hline upper yield point $R_{\mathrm{e}}$ & $455.0 \mathrm{MPa}$ & & ultimate tensile stress $\mathrm{R}_{\mathrm{m}}$ & $537.4 \mathrm{MPa}$ \\
\hline proof stress $\mathrm{R}_{\mathrm{p} 0.2}$ & $433.5 \mathrm{MPa}$ & & uniform elongation $\mathrm{e}_{\mathrm{m}}$ & $16.1 \%$ \\
\hline $0.5 \%$ strain offset $\mathrm{R}_{\mathrm{t} 0.5}$ & $433.5 \mathrm{MPa}$ & & yield-to-tensile ratio $\mathrm{R}_{\mathrm{p} 0.2} / \mathrm{R}_{\mathrm{m}}$ & 0.83 \\
\hline Lüders elongation $\mathrm{e}_{\text {Lüders }}$ & $2.62 \%$ & \multicolumn{4}{|l}{} \\
\hline
\end{tabular}

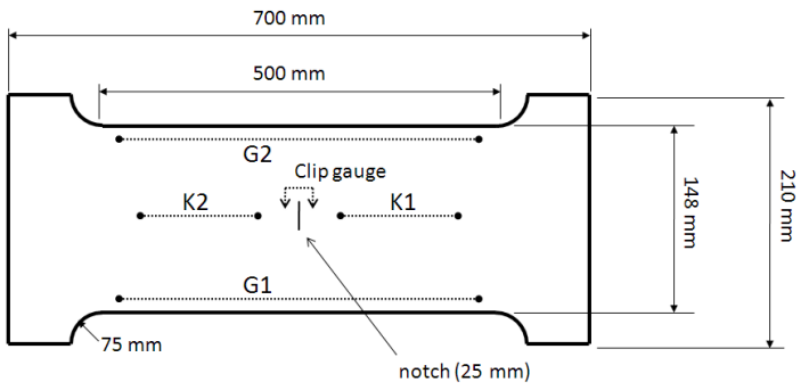

Figure 2: Geometry and mounting positions of measurement devices (figure not to scale)

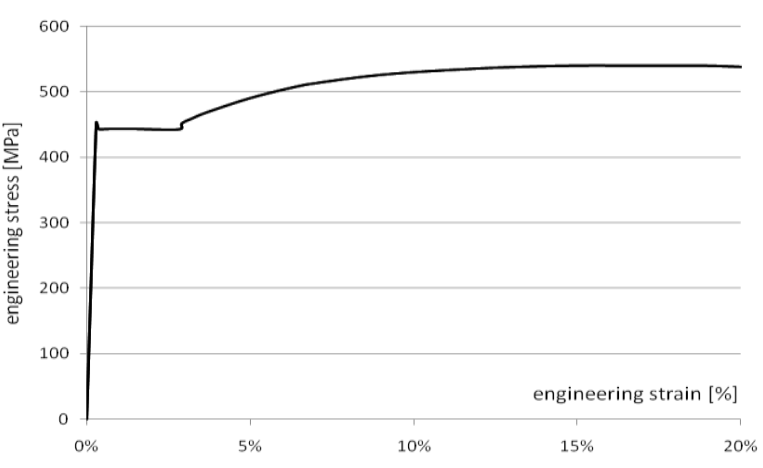

Figure 3: Longitudinal stress-strain curve of the material

For optical strain measurements, a randomly distributed speckle pattern was applied on the notched side of the specimen. The speckle pattern was obtained from a uniform layer of white spraying paint covered with spots of black lacquer paint. This pattern allows the Digital Image Correlation (DIC) camera system to track different regions of the MWP during the experiment. More information on this system is given in section 2.3.3. To avoid crumbling of the paint layer during the test, the corrosion layer on the specimen was removed in advance.

\subsection{Test rig and measurement equipment}

\subsubsection{MTS test rig}

A servo-hydraulic MTS universal test rig was used for this experiment. The system can exert a maximum force of $2500 \mathrm{kN}$ and a maximum piston displacement of $150 \mathrm{~mm}$. 


\subsubsection{LVDTs and clip gauge}

To measure the deformation at different locations of the specimen, 4 LVDTs were mounted on the backside of the specimen according to the UGent guidelines for CWP testing [4]. Two of them with gauge length 108 $\mathrm{mm}$ (K1 and K2) were located in the gross section of the specimen, away from the notch. The two other LVDTs (G1 and G2), with gauge length $388 \mathrm{~mm}$, measured the elongation of the full prismatic section, traversing the defected section. Their position is indicated in Figure 2.

A clip gauge was put over the notch to measure the crack mouth opening displacement (CMOD).

\subsubsection{DIC camera system}

Digital Image Correlation (DIC) is an optical method in which the movement of speckle dots is tracked to calculate their displacement. From this displacement, strain fields on the surface of the specimen can be determined. In this experiment, a setup of two cameras is used to allow 3D vision, so out-of-plane deformations (eg. necking) of the specimen can be evaluated as well. Both cameras are synchronized and take one picture of $5 \mathrm{Mpx}$ every 10 seconds. A laptop with control and processing software also recorded the analogous force signal to allow for synchronization of the DIC and LabVIEW measurements.

A crucial element in the DIC technique is the size of the speckle dots. Dots should not be too small for the cameras to detect them. If they are too large, however, calculation accuracy is reduced. The speckle pattern shown in Figure 4 and Figure 5 did not introduce any correlation issues. The strain resolution was of the magnitude $0.1 \%$ strain.

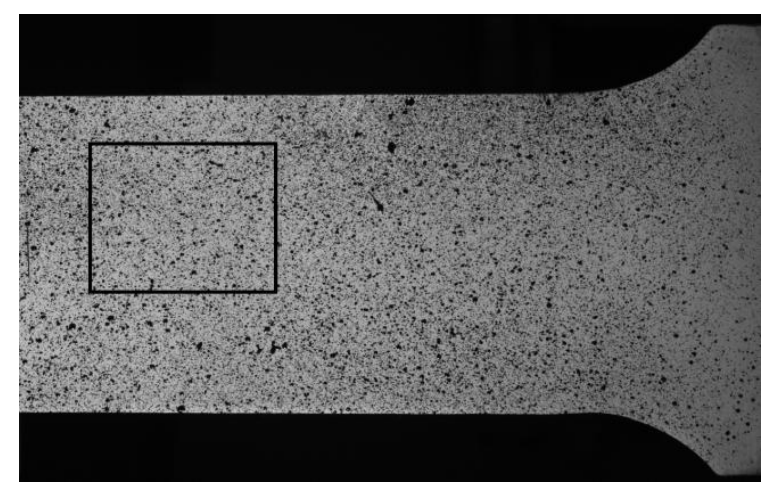

Figure 4: View of speckle pattern on half of the MWP specimen

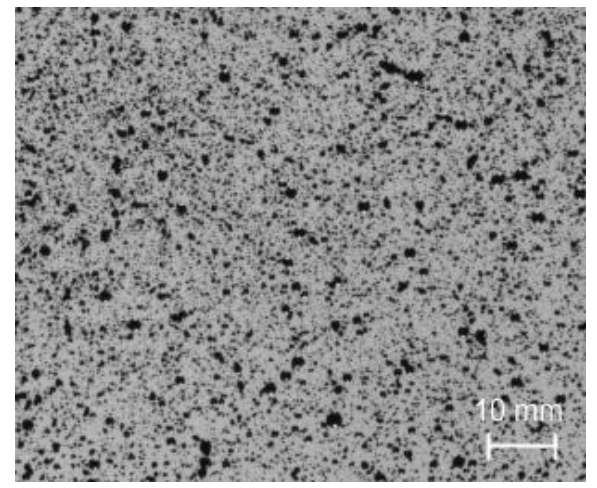

Figure 5: Detailed view of Figure 4.

\subsection{Software}

A LabVIEW program was developed to control the test rig. The software defines whether the test rig should load or unload the specimen or hold it in a fixed position, based upon measurements of CMOD and applied force. In fact, a simple tensile test would suffice to validate the FEM model, but it was opted to follow the unloading compliance method [5]. Unloading compliance is a technique whereby the specimen is sequentially loaded and unloaded, first in the elastic region, then in the plastic region. In the latter case, the unloading decision is based on a constant increment of CMOD. When plotting applied force as a function of CMOD, as in Figure 6, different loading and unloading cycles can be seen. From the slope evolution of the unloading and reloading cycles, crack size can be determined. 


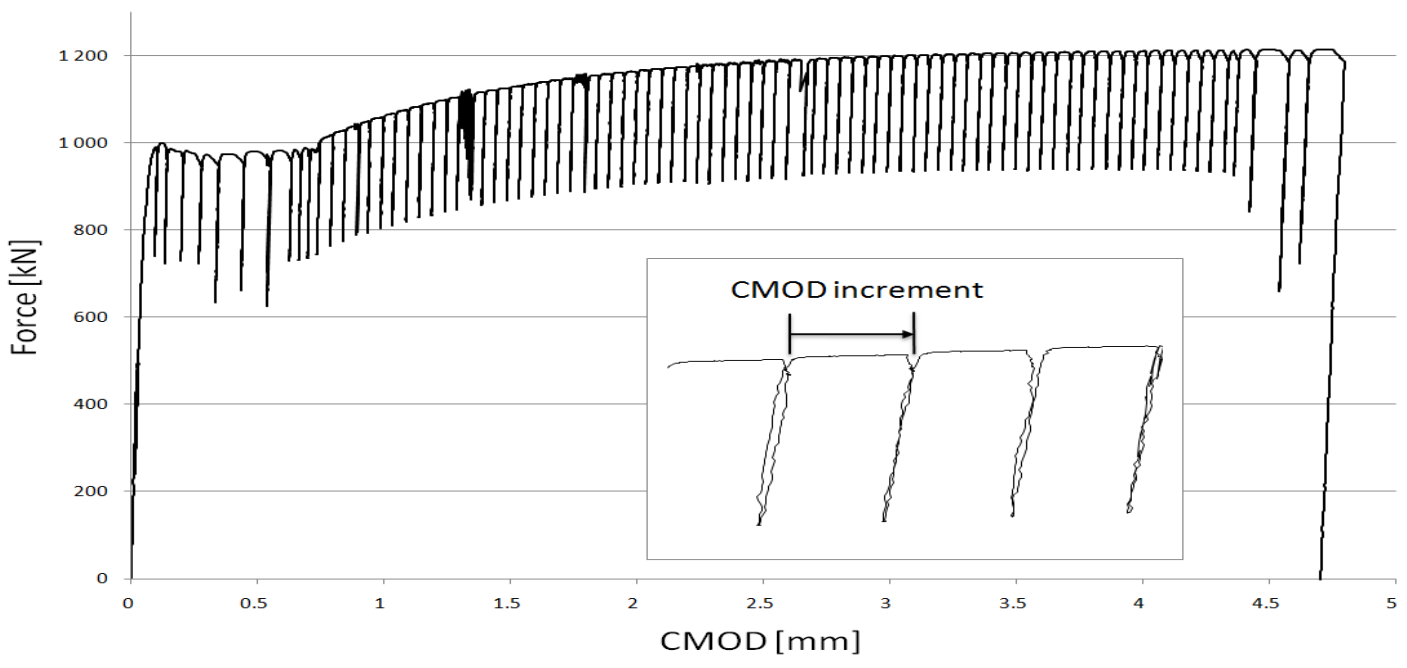

Figure 6: Force with respect to CMOD

The software provides a parametric input of characteristics related to the unloading compliance cycles, for instance the required CMOD increment between two cycles. When the program is started, it runs through a state diagram, defining different cases of how the controller should behave. Depending on the obtained force or CMOD, the software deliberately switches between cases. When detecting failure, all case decisions are overruled by a safety mechanism and the test specimen is unloaded. The use of a state diagram makes the software robust as decisions are not influenced by irrelevant measurements.

All LVDT displacements, CMOD, force and piston displacement have been monitored in the LabVIEW software and logged into a database at a rate of $10 \mathrm{~Hz}$.

\subsection{Execution of the test}

No significant problems were recorded except for some temporary malfunctioning of the hydraulic valves, which caused an oscillating force (see Figure 6 around $1.3 \mathrm{~mm}$ CMOD). Because of a too small CMOD increment setting, as much as 85 cycles were executed. Eventually, it was chosen to end the test when CMOD started increasing drastically, announcing a necking phenomenon in the defective section (net section collapse). A maximum piston displacement of $77.6 \mathrm{~mm}$ and force of $1215 \mathrm{kN}$ were measured. The CMOD eventually obtained was $4.8 \mathrm{~mm}$.

\subsection{Post-mortem analysis}

After testing the specimen, a macro section of the notch region was cut out (Figure 7). This section indicates a stable crack extension of $2 \mathrm{~mm}$ in the through-thickness direction, and confirms necking in the defective section.

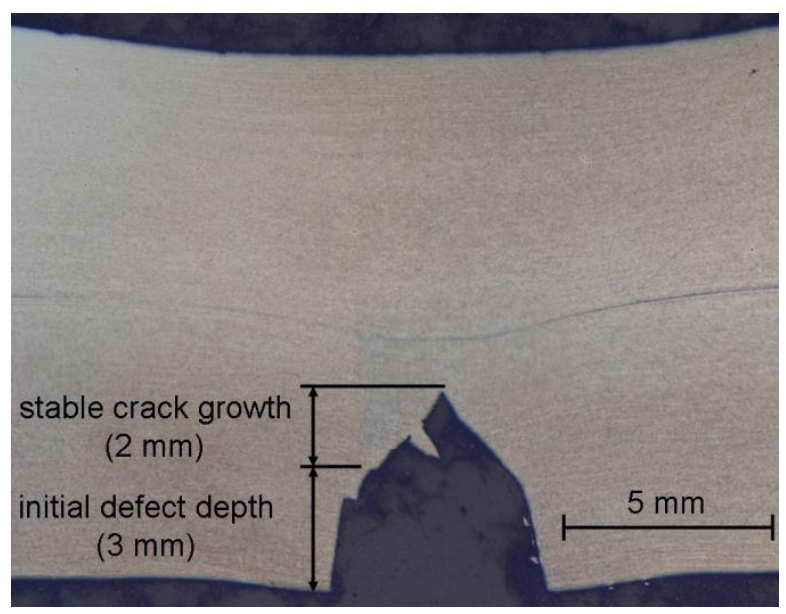

Figure 7: Macro section of the notch 


\section{FINITE ELEMENT MODEL}

A parametric finite element model of a curved wide plate has been previously developed at Laboratory Soete. Mesh density was defined according to an existing mesh convergence study. This resulted in the mesh shown in Figure 8 and Figure 9. Clamped boundary conditions were imposed at the end nodes of two rigid blocks, attached to the actual wide plate specimen.

The stress-strain curve before necking was converted from engineering values to true stress and true strain. For the curve after necking, the approach recommended in [6] was followed. This method calculates a weighted-average of an upper and lower bound. The upper bound is a linear extrapolation, the lower bound a power law extrapolation. A weight factor between the two curves should be iteratively defined to match experimental results, and was chosen 0.5 in this case.

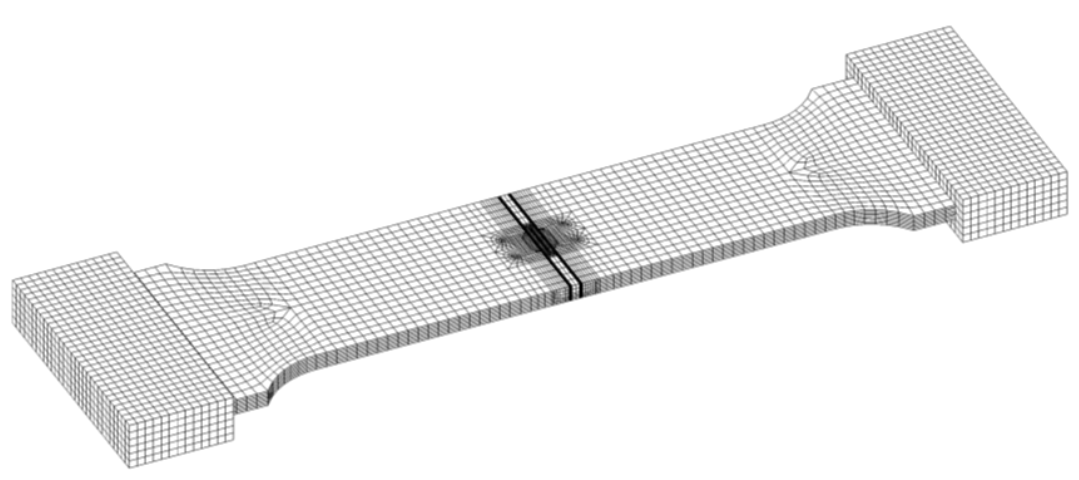

Figure 8: Global FE model (geometry and mesh) of the specimen

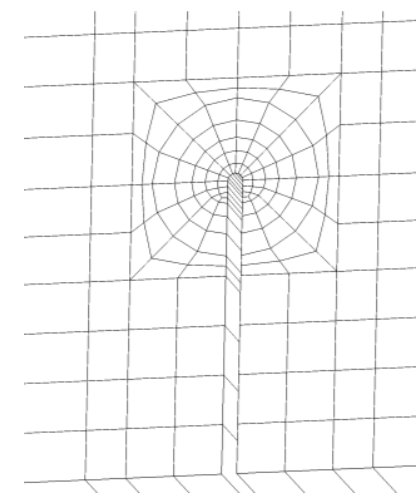

Figure 9: Detailed view of the mesh at the notch region

\section{DISCUSSION}

\subsection{Comparison of DIC and LVDT measurements}

To validate the strain field calculations by the DIC software, engineering strain was compared with the strain calculated from the LVDT elongation measurements. Because both datasets described the same experiment, displacement of the pistons was chosen as the common basis for the comparison. The plots in Figure 10 and Figure 11 display the engineering strain measured at the two small LVDTs, K1 and K2.

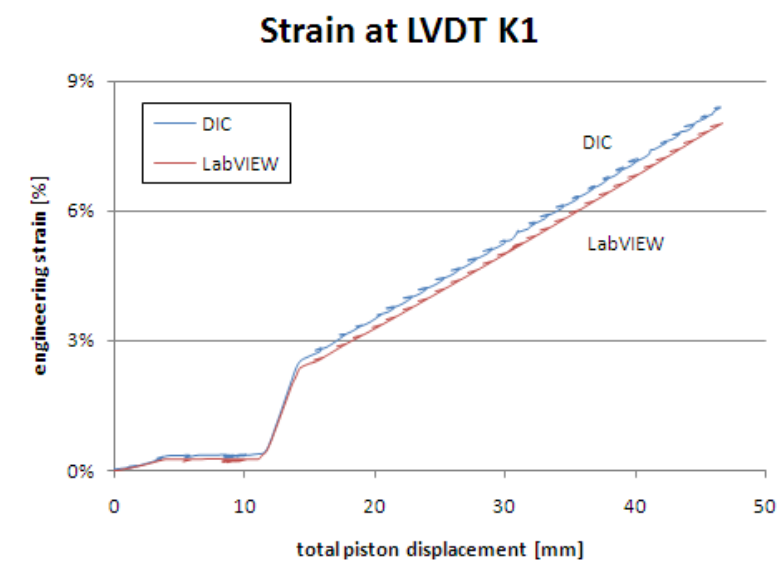

Figure 10: Engineering strain calculated by DIC and measured by LVDT K1

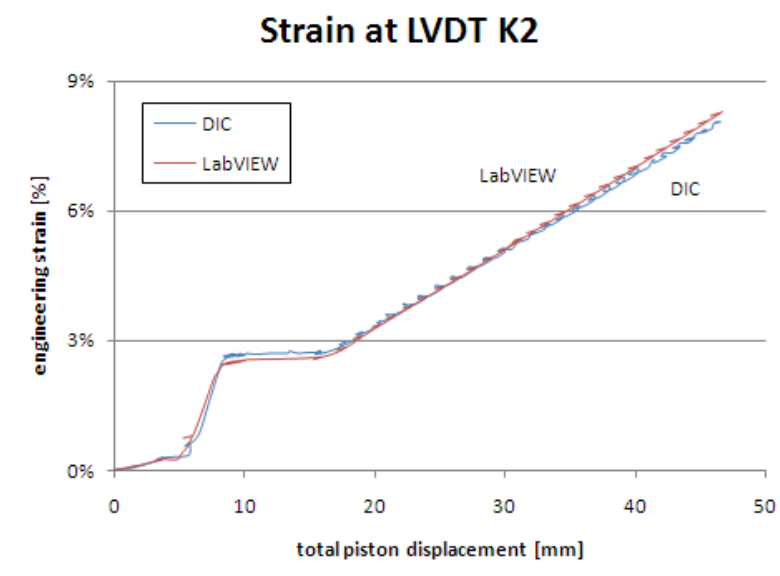

Figure 11: Engineering strain calculated by DIC and measured by LVDT K2

When the piston displacement reached about $45 \mathrm{~mm}$, the boundaries of the LVDTs linear operation range were exceeded, so comparison is limited to this area. The small ripples visible on the curves are caused by the unloading compliance cycles. It can be seen that both strain measurements are in (very) good agreement. The correspondence with the large LVDTs (G1 and G2), which did not saturate, is excellent (Figure 12 and Figure 13). The small "hooks" at the right top corner indicate unloading at the end of the test. 
Strain at LVDT G1

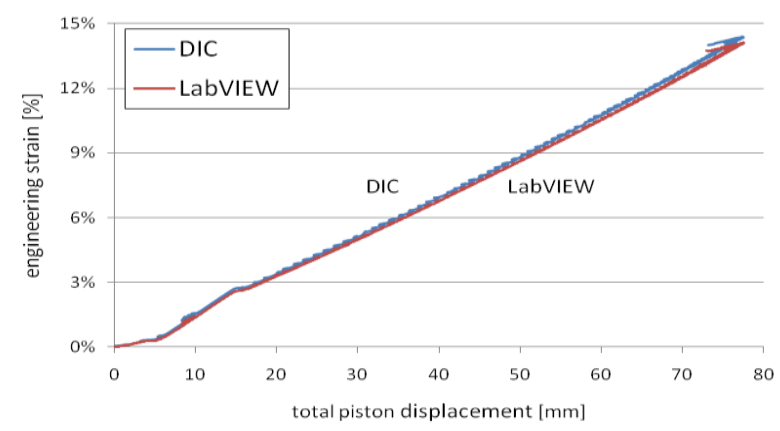

Figure 12: Engineering strain calculated by DIC and measured by LabVIEW at LVDT G1
Strain at LVDT G2

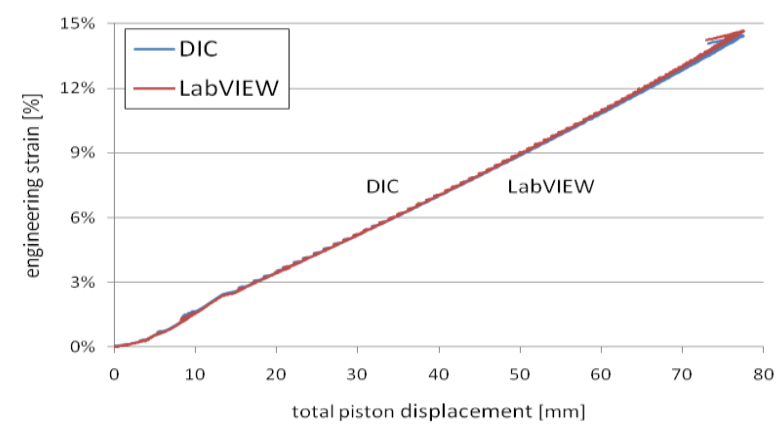

Figure 13: Engineering strain calculated by DIC and measured by LabVIEW at LVDT G2

A detailed view of the $\mathrm{K} 1$ and $\mathrm{K} 2$ engineering strains at both sides of the notch is shown in Figure 14. The large increments of the strain calculated from both LVDT measurements are caused by the Lüders behaviour of the material. The first region experiencing Lüders behaviour is the K2 region. Roughly between 1000 seconds and 1250 seconds, the material at the K2 side yields while the strain at the K1 region remains constant. From 2750 seconds to 3000 seconds, the behaviour is opposite. In the interval between these periods, the region around the crack yields. Although this is a small region, it took a long time before the Lüders yielding ended due to a large number of unloading cycles. If the material around the crack is yielding, a CMOD increment is easily obtained, causing the system to hold, unload, hold and load again. The CMOD curve in Figure 14 illustrates this behaviour. CMOD increases in steps when the material around the crack is yielding, while remaining constant when the $\mathrm{K} 2$ and $\mathrm{K} 1$ zones yield.

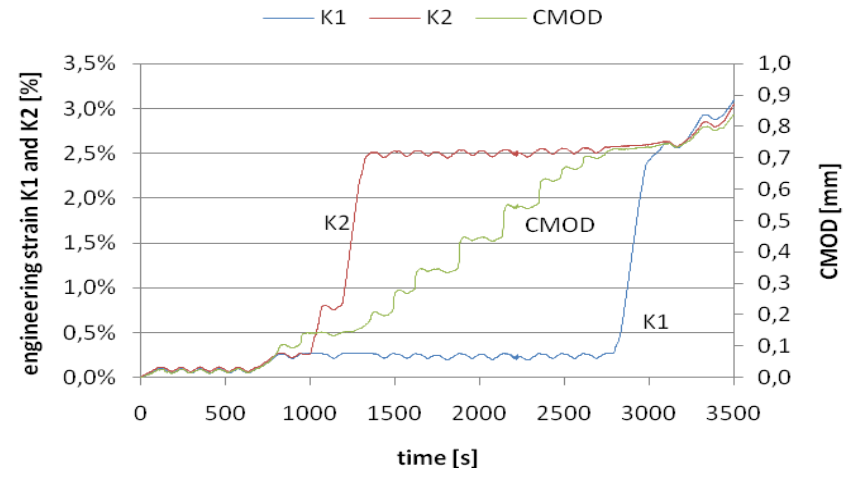

Figure 14: Detailed view of Lüders behaviour at both sides of the specimen

\subsection{Comparison of FEM results with DIC measurements}

Comparison of the numerical and experimental results is far from straightforward. First, the experiment followed the unloading compliance procedure with loading and unloading cycles, while ABAQUS simulates a monotonically increasing tensile load. Second, the finite element model predicted symmetrical results while small natural variations in material and geometrical properties caused an asymmetrical Lüders yielding. Third, the specimen's mounting blocks elastically deform during the test while modelled as rigid blocks in ABAQUS. Due to this and initial backlash in the test rig, a comparison based on total (piston) displacement is not possible. Fourth, crack growth, and subsequent influence on the strain fields, was not modelled in ABAQUS. Because of these reasons, the engineering strain fields of the simulation were compared to those of the DIC measurement at frames corresponding to a fixed and limited LVDT strain, more specifically the frames corresponding to LVDT strains $\varepsilon_{\mathrm{K} 1}$ of $4 \%$ and $7 \%$. With these values, the Lüders behaviour is avoided and the ductile crack extension can be assumed negligible.

Inspection of the contour plots of the first principle strain (Figure 15 and Figure 16) yields a good agreement (both qualitative and quantitative) between the calculated and measured results. It should be noted that ABAQUS plots logarithmic strain while the DIC-software plots Lagrange strain. However, the difference between both is small. An expected X-shaped strain concentration around the notch is visible on both plots. Figure 17 and Figure 18 are plots of the strain values along the paths defined in Figure 15 and Figure 16. ABAQUS successfully predicted strain hotspots in front of the shoulders, which may harm the capability of LVDT measurements to indicate a far-field uniform strain. In the experiment, the hotspot at the right side of the notch was more pronounced than the left one. ABAQUS overestimates this hotspot in Figure 17, 
whereas it is underestimated in Figure 18. This indicates that the experiment is prone to inevitable coincidences and natural effects which are not (or even cannot be) accounted for in the simulation. Nevertheless, a more than satisfactory overall agreement is observed between the experimental and the simulated results.
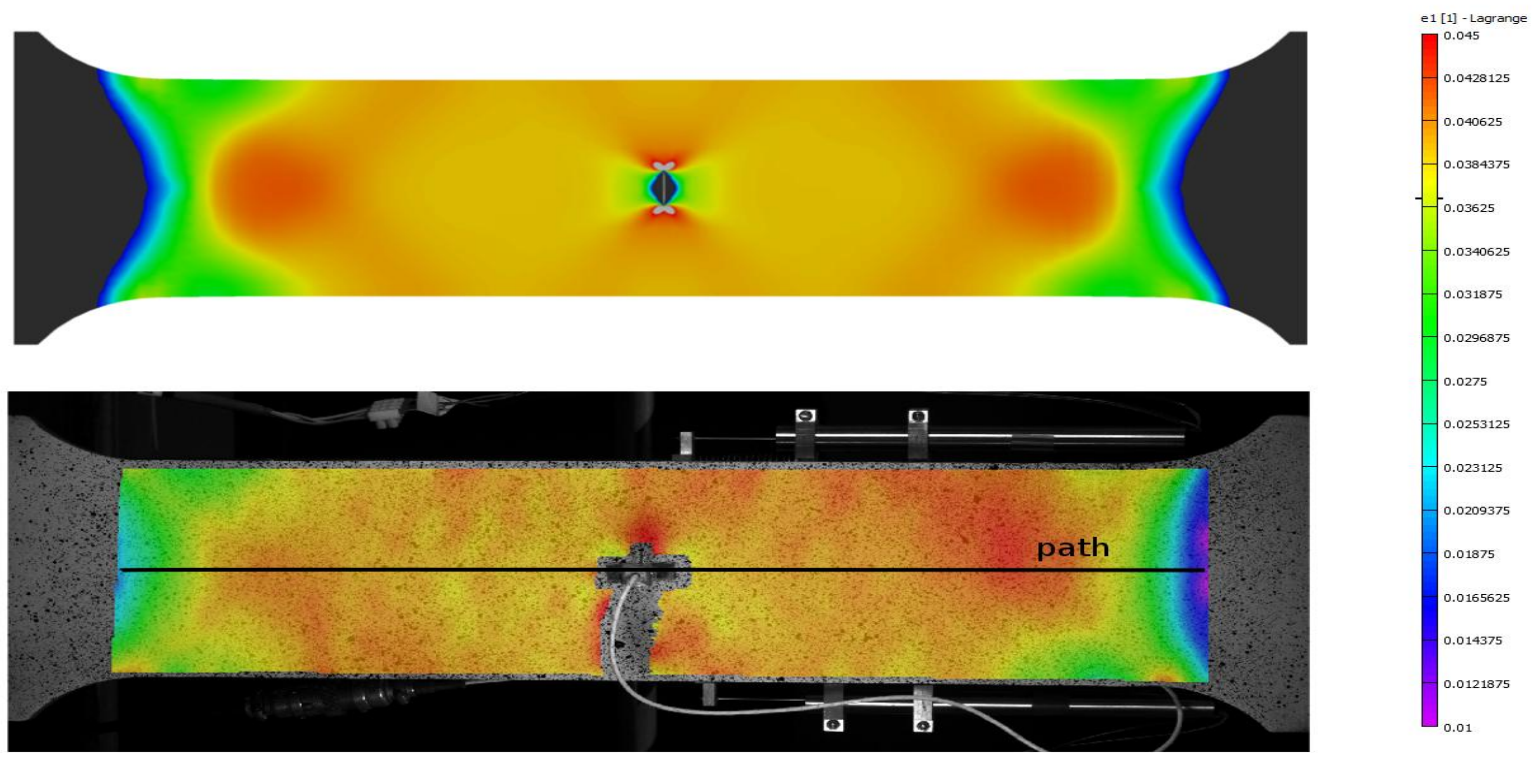

Figure 15: First principal strain for $\varepsilon_{\mathrm{k} 1}=4 \%$

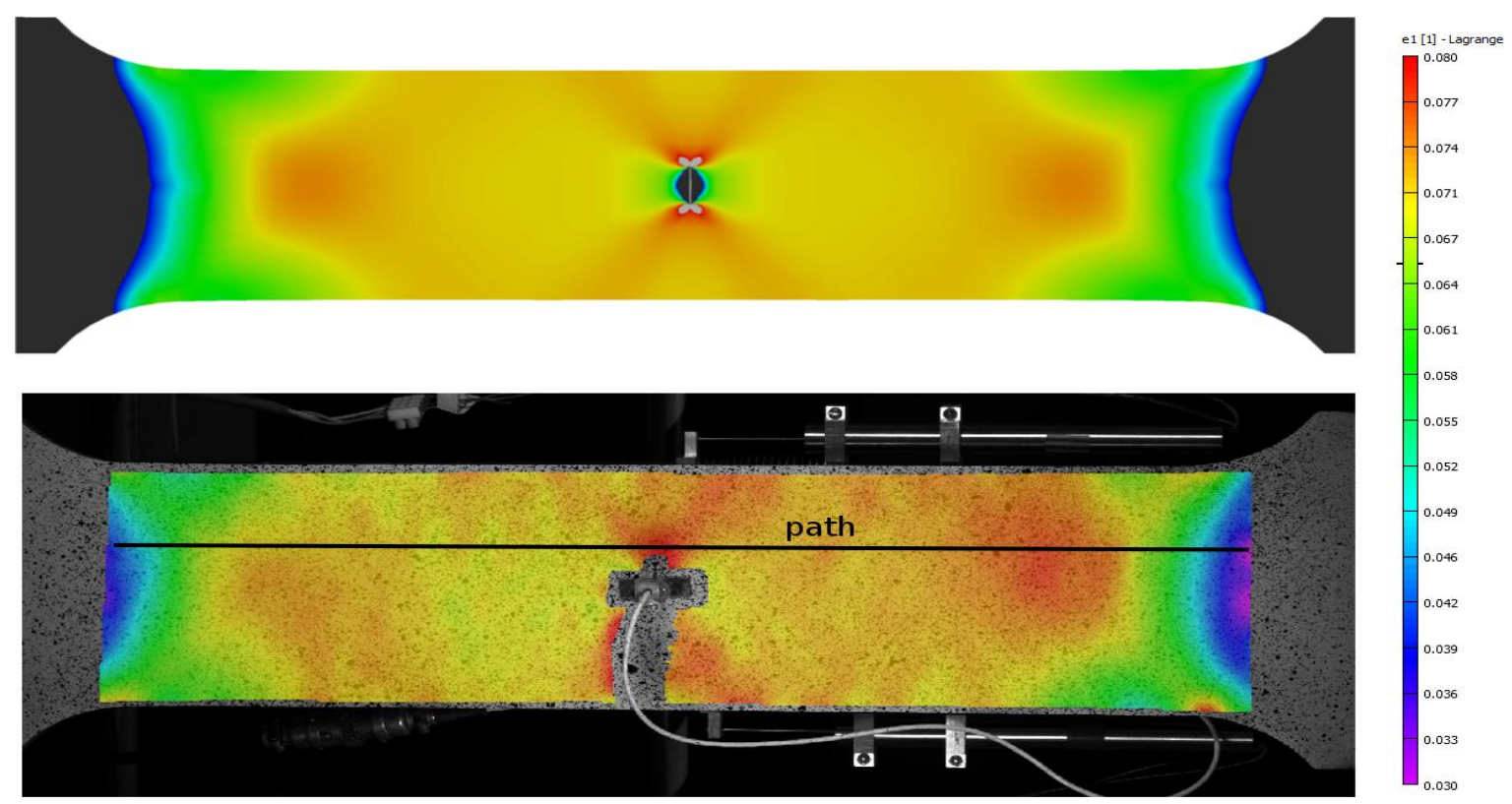

Figure 16: First principal strain for $\varepsilon_{\mathrm{K} 1}=7 \%$

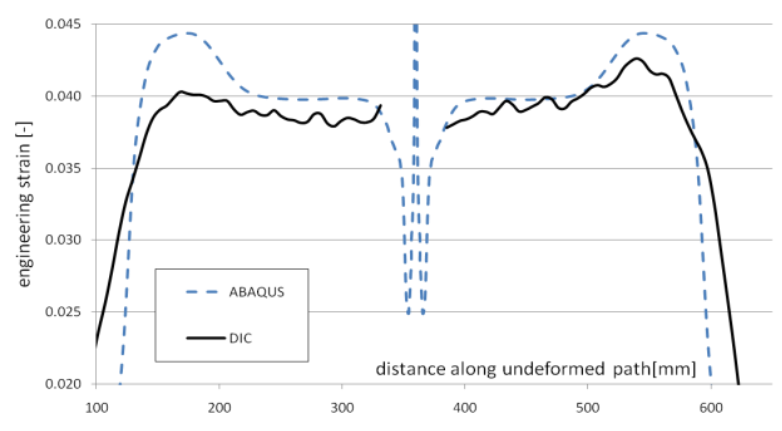

Figure 17: First principal strain along path for $\varepsilon_{\mathrm{K} 1}=4 \%$

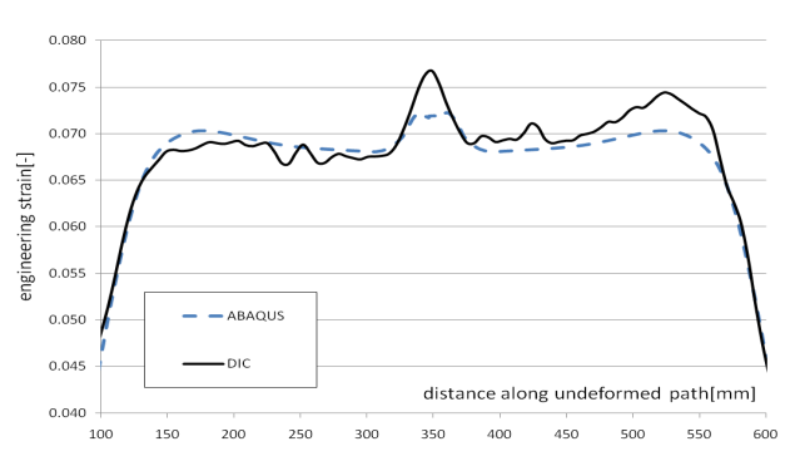

Figure 18: First principal strain along path for $\varepsilon_{\mathrm{K} 1}=7 \%$ 


\section{CONCLUSIONS}

The optical strain measurement (DIC) results show good accordance with the LVDT measurement results. Although comparison on the small LVDTs was limited to a maximum strain of $8 \%$, there seems to be a very good similarity between the measurements. The major advantage of the DIC system is that it provides strain field output of the whole surface of the specimen. A disadvantage is the time-consuming and sensitive procedure required to speckle the specimen.

The ABAQUS finite element model predicts the MWP's strain fields fairly well for strains higher than the maximum Lüders strain. Further, crack growth is not yet implemented in the model, so application of the current model at large strains, where ductile crack extension has a significant influence, is discouraged as well.

Although no correlation problems were noted, more accurate DIC results might be obtained when an optimized speckle pattern is applied to the specimen. A study on the influence of the speckle size and how to create speckles in a controlled manner is suggested.

\section{NOMENCLATURE}

DIC Digital Image Correlation

CMOD Crack Mouth Opening Displacement

CWP Curved Wide Plate

LVDT Linear Variable Displacement Transducer

MWP Mini Wide Plate

UC Unloading Compliance

\section{ACKNOWLEDGEMENTS}

The authors would like to acknowledge the support of the technical staff of Laboratory Soete and the Belgian Welding Institute (Wouter Ost, Hans Van Severen, Julien De Meyer, Johan Van Den Bossche, Philip De Baere) during preparation, mounting, unmounting and post-mortem analysis of the performed mini wide plate test. The authors also acknowledge the financial support of the FWO (Research Foundation) Flanders (grants nr. 1.1.880.09N, 1.5.247.08N.00) and the IWT (Agency for innovation by science and technology; grant nr. SB-091512).

\section{REFERENCES}

[1] J. Rupert, G.Tart, Pipeline geohazards unique to northern climates, Proceedings of the 8th International Pipeline Conference, Calgary, Alberta, Canada, 2006.

[2] W. Mohr, Strain-based design of pipelines, October 2003. EWI Report Project No.45892GTH.

[3] API 5L, Specification for Line Pipe, 42nd edition, American Petroleum Institute, 2000.

[4] R. Denys, A. Lefevre, UGent guidelines for curved wide plate testing, Proceedings of the $5^{\text {th }}$ Pipeline Technology Conference, Ostend, Belgium, 2009.

[5] S. Cravero, C. Ruggieri, Estimation procedure of J-resistance curves for $\mathrm{SE}(\mathrm{T})$ fracture specimens using unloading compliance, Engineering Fracture Mechanics, 74, 2735-2757, 2007.

[6] Y.Ling, Uniaxial True Stress-Strain after Necking, AMP Journal of Technology, 5, 37-48, 1996. 